\title{
Fluid-mixing induced iron-sulfur isotope decoupling recorded in a large hydrothermal system
}

\author{
ZHAOFU GAO AND XIANGKUN ZHU* \\ MNR Key Laboratory of Isotope Geology, MNR Key \\ Laboratory of Deep-Earth Dynamics, Institute of Geology, \\ Chinese Academy of Geological Sciences, Beijing \\ 100037, China (*correspondence: xiangkun@cags.ac.cn)
}

Most of the world's giant sediment-hosted massive sulfide (SHMS) deposits are Paleo- to Mesoproterozoic in age and characterized by common occurrence of ${ }^{34} \mathrm{~S}$ enrichments. Several giant $\mathrm{Zn}-\mathrm{Pb}$ deposits in the LangshanZhaertai polymetallic ore district (Inner Mongolia, Northern China), especially the Dongshengmiao and adjacent Tanyaokou deposits, to the best of our knowledge, are the most heavy sulfide ore deposits in the world. The Dongshengmiao deposit has been exploited for nearly 50 years and represents the most representative Proterozoic SHMS deposit in China. Together with early geological and geochemical evidence, the data of disseminated pyrites and associated nodlles demonstrate the host rocks form under an oxidized shallow-water to evaporitic environment and the generally high $\delta^{34} \mathrm{~S}$ values (mostly $20-25 \%$ ) represent closedsystem sulfide production in sediment porewater and positive $\delta^{56} \mathrm{Fe}$ values represent diagenetic conversion of ferric (oxyhydr) oxides, which were partially oxidized by the $\mathrm{Fe}^{2+}$ in the seawater. These characteristics are consistent with ubiquitous replacement and rarely-occurred laminated textures of the Dongshengmiao ores. The shared positive values and stratigraphic trends in the massive ore sulfides and diagenetic pyrites indicate a shared sulfur source, most likely seawater sulfate trapped in systems closed to sulfate beneath the water-sediment interface. Systematic $\mathrm{Fe}-\mathrm{S}$ isotope decoupling at the deposit scale has been documented. Variable $\mathrm{Fe}$ isotope values within the $\mathrm{Zn}-\mathrm{Pb}$ orebody coincide with rather constant $\mathrm{S}$ isotope values and vice versa in the upper pyrite orebodies. The imcomplete mixing of lower metal- and upper S-end menmber result in the transation from $\mathrm{Fe}$ - to $\mathrm{S}$-exess in the main stage massive sulfide mineralization, which is an important factor affecting the types of ore and their isotopic composition. Furthermore, the extremely high $\delta^{34} S_{\text {barite }}$ values is consistent with a restricted system model of sulfate reduction, in which reduced sulfur generation occurred with a reduced isotopic fractionation $(<10 \%)$ linked to higher rates of sulfate reduction. 